Neuerscheinung

Dipl.-Phys. M. MARVAN

\title{
Negative absolute Temperaturen
}

\author{
Mathematisch-Naturwissenschaftliche Bibliothek, Bd. 40 \\ Übersetzung aus dem Tschechischen: Sophia Hellebrand \\ Redaktion: Dr. H. Schneider, Dr. G. Specht \\ 66 Seiten mit 27 Abbildungen - L 7 N - In Halbleinen 10,50 M
}

\begin{abstract}
Nach der Definition der Temperatur gemäß den klassischen Gesetzen der Thermodynamik erscheint eine negative absolute Temperatur absurd. In dem Bändchen wird nun gezeigt, daß quantenphysikalisch bei einem Ensemble von Teilchen, für die nur eine begrenzte Anzahl von Energiezuständen möglich ist, der Fall eintreten kann, daß die Zustände höherer Energie stärker besetzt sind als die Zustände geringerer Energie; in diesem Fall hat das betrachtete System eine negative absolute Temperatur. - Die Zustände mit negativer absoluter Temperatur finden sich z. B. im Maser und Laser realisiert.
\end{abstract}

\section{宙}

B. G. TEUBNER VERLAGSGESELLSCHAFT LEIPZIG

\section{BEZUGSMÖGLICHKEITEN}

Sämtliche Veröffentlichungen unseres Verlages sind durch jede Buchhandlung im In- und Ausland zu beziehen. Falls keine Bezugsmöglichkeit vorhanden ist, wende man sich in der Deutschen Demokratischen Republik an den AKADEMIE-VERLAG, GmbH, 108 Berlin, Leipziger Straße 3-4

in der Deutschen Bundesrepublik an KUNST UND WISSEN, Erich Bieber, 7 Stuttgart 1, Wilhelmstraße 4-6

in Österreich an den GLOBUS-Buchvertrieb, Wien I, Salzgries 16

in Nord- und Südamerika

an Gordon and Breach Science Publishers, Inc., 150 Fifth Avenue, New York, N. Y. 10011 U.S.A.

bei Wohnsitz im übrigen nichtsozialistischen Ausland

an den Deutschen Buch-Export und -Import GmbH, 701 Leipzig, Leninstraße 16.

Im sozialistischen Ausland können Bestellungen über die Buchhandlungen für fremdsprachige Literatur bzw. den zuständigen Postzeitungsvertrieb erfolgen.

Auf Wunsch sendet der AKADEMIE-VERLAG Interessenten bei Bekanntgabe der Anschrift und Fachgebiete unverbindlich Informationen über lieferbare und kommende Veröffentlichungen und gibt auch Bezugsquellen im In- und Ausland bekannt. 